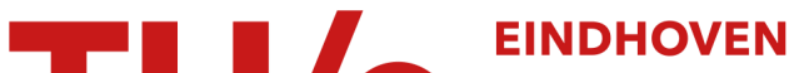 \\ UNIVERSITY OF \\ TECHNOLOGY
}

\section{Soft-landing control of low-energy solenoid valve actuators}

Citation for published version (APA):

van Dam, J. R. M., Gysen, B. L. J., Lomonova, E. A., \& Dhaens, M. (2018). Soft-landing control of low-energy solenoid valve actuators. In 2018 13th International Conference on Ecological Vehicles and Renewable Energies, EVER 2018 [8362372] Institute of Electrical and Electronics Engineers.

https://doi.org/10.1109/EVER.2018.8362372

DOI:

10.1109/EVER.2018.8362372

Document status and date:

Published: 21/05/2018

Document Version:

Accepted manuscript including changes made at the peer-review stage

Please check the document version of this publication:

- A submitted manuscript is the version of the article upon submission and before peer-review. There can be important differences between the submitted version and the official published version of record. People interested in the research are advised to contact the author for the final version of the publication, or visit the $\mathrm{DOI}$ to the publisher's website.

- The final author version and the galley proof are versions of the publication after peer review.

- The final published version features the final layout of the paper including the volume, issue and page numbers.

Link to publication

\section{General rights}

Copyright and moral rights for the publications made accessible in the public portal are retained by the authors and/or other copyright owners and it is a condition of accessing publications that users recognise and abide by the legal requirements associated with these rights.

- Users may download and print one copy of any publication from the public portal for the purpose of private study or research.

- You may not further distribute the material or use it for any profit-making activity or commercial gain

- You may freely distribute the URL identifying the publication in the public portal.

If the publication is distributed under the terms of Article $25 \mathrm{fa}$ of the Dutch Copyright Act, indicated by the "Taverne" license above, please follow below link for the End User Agreement:

www.tue.nl/taverne

Take down policy

If you believe that this document breaches copyright please contact us at:

openaccess@tue.nl

providing details and we will investigate your claim. 


\section{Soft-landing control of low-energy solenoid valve actuators}

\author{
J. R. M. van Dam, B. L. J. Gysen, E. A. Lomonova \\ Eindhoven University of Technology \\ Department of Electrical Engineering \\ Eindhoven 5612 AP, The Netherlands \\ Email: j.r.m.v.dam@tue.nl
}

\author{
M. Dhaens \\ Tenneco Automotive Europe BVBA \\ Advanced Chassis Research \\ B 3800 Sint-Truiden, Belgium
}

\begin{abstract}
An automotive, fluid-control solenoid valve is composed of an electromagnetic reluctance actuator and a near-constant-force spring. Its motion profile is characterized by short closed-to-open transition times which demand fast switching, while valve lifetime improves by minimizing the impact velocity, i.e. a soft landing. In this paper, a cascaded position- and current-feedback control is designed and implemented on nonlinear, axisymmetric magnetostatic finite element simulations of a low-energy solenoid valve actuator. By applying the cascaded control, actuator performance is improved considerably, as a soft landing, a timely actuation, and an increased energyefficient device have been obtained.
\end{abstract}

Keywords-Actuators, Control, Magnetostatic.

\section{INTRODUCTION}

An automotive, fluid-control solenoid valve is composed of an electromagnetic reluctance actuator and a near-constant-force spring. Reluctance actuators are applied as electromagnetic brakes in aerospace applications [1], as valves that perform fast sorting tasks by means of short air-pulses in the manufacturing industry [2], as accurate fluid-control valves in petrochemical processes [3], and in the automotive industry to achieve variable valve timing in camless engines [4]. Common desires are a fast switching and low noise upon impact. Preferably, these objectives are met with minimized energy consumption, especially during constant position operation. In addition, minimizing the impact velocity improves valve lifetime and reduces the audible noise, vibration, and harshness (NVH).

Several energy minimization strategies for electromagnetic valve actuators (EVAs) exist. The valve geometry can be adjusted to closely match the electromagnetic force-displacement characteristic to the desired force [5], which allows to minimize the required coil current. In addition, pre-biasing a reluctance actuator with a permanent magnet (PM) further reduces the required electrical energy during latching [3], despite the additional energy demand during motion. Bouncing of the valve can be countered through closed-loop control using position feedback, which is implemented based on measurements of electrical quantities at the coil terminals in [6], although the proposed technique works best for repetitively operating devices. In addition, iterative learning control aims to close the feedback loop by directly measuring the plunger position [4], while a position estimator achieved (sub-)millimeter position errors [7]. Shaping of the position reference helps the motion control of EVAs to achieve a soft landing during the opening and closing motions [2].

This paper discusses the design of a cascaded position and current control applied to a fluid bypass EVA to track a soft-landing motion reference. Modeling is performed using nonlinear, magnetostatic finite element (FE) simulations where the axial symmetry of the actuator is used to reduce the problem complexity. These simulation results are used to populate lookup tables (LUTs) to allow for fast simulations. The limitations of the proposed simulations and control method are addressed as well.

\section{ACTUATOR TOPOLOGIES}

In the considered application, a linear reluctance actuator works to open and close a $1.2 \mathrm{~g}$ valve plunger against opposing oil and spring forces of 4 to 12 N. Figure 1 shows the investigated single-coil reluctance actuators, where Fig. 1a depicts a classical reluctance actuator (CLA), consisting of a soft-magnetic core around which a coil is wound. Magnetic flux created by the coil windings works to close the primary airgap and, hence, to attract the solid steel plunger (mover) upwards in the direction of the core. A means to bias the airgap flux is shown in Fig. 1b, where a permanent magnet (PM) is added atop the core. As a result, a zero-power attractive force works on the mover and can, theoretically, hold closed 

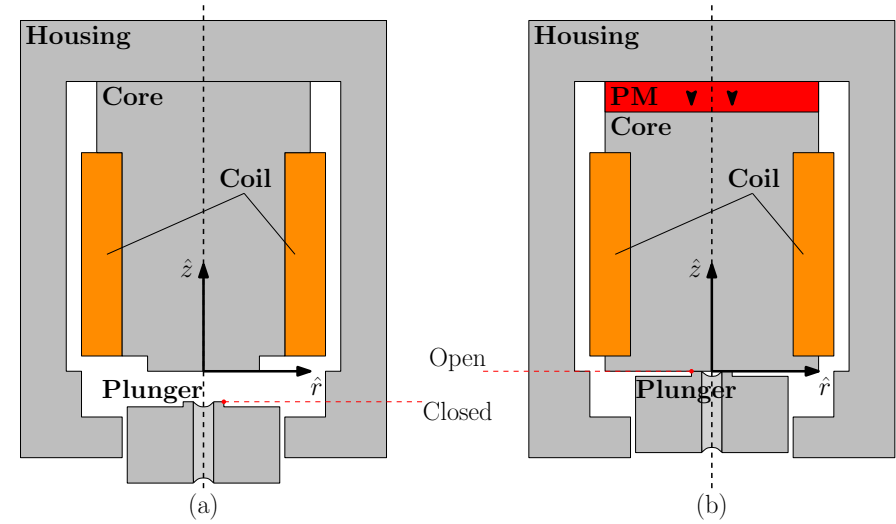

Fig. 1. Cross-section views of the considered valve actuators with (a) the classical reluctance actuator (CLA), and (b) the permanent magnet-biased reluctance actuator (PMB).

the mover to the stator (latch) [1], [3], [8]. Again, a coil is wound around a steel core, however, contrary to CLA, in this permanent magnet-biased (PMB) actuator, the coil only operates to change the mover position, whereas in CLA, continuous consumption of electrical energy is required to latch the plunger. In addition, the actuator height and diameter are constrained to 16 and $13 \mathrm{~mm}$, with a $0.25 \mathrm{~mm}$ airgap. Note that the scope of this paper is limited to CLA.

\section{CONTROLLED SOFT-LANDING}

Analyses on two reluctance actuators have shown that open-loop control using predefined voltage profiles results in high energy consumption and no soft-landing (see Fig. 4(a)). Furthermore, the eddy current effects further deteriorate the timing performance and increase the losses. To achieve soft-landing and further minimization of energy consumption during movement and holding, cascaded closed-loop control is considered, i.e. inner and outer feedback loops to control the current and position, respectively. Eddy current effects are neglected in this analysis, as the main objective is to show the possibility of using feedback control to soft-land the valve plunger.

Minimization of the impact velocity can be achieved by tracking a second-order position reference, as shown in Fig. 2. This motion profile is tuned to achieve a stroke of $0.25 \mathrm{~mm}$ in $4 \mathrm{~ms}$, while having a zero impact velocity, i.e. a soft landing, at both extreme positions. A constant position is attained by the valve during two periods in a single motion cycle, indicated by closed and open in Fig. 1.

The proposed cascaded control structure is presented in Fig. 3, which includes a current controller, $C_{\mathrm{i}}$, and a position controller, $C_{\mathrm{z}}$. Next, modeling of the actuator and the design of the feedback controllers is discussed.

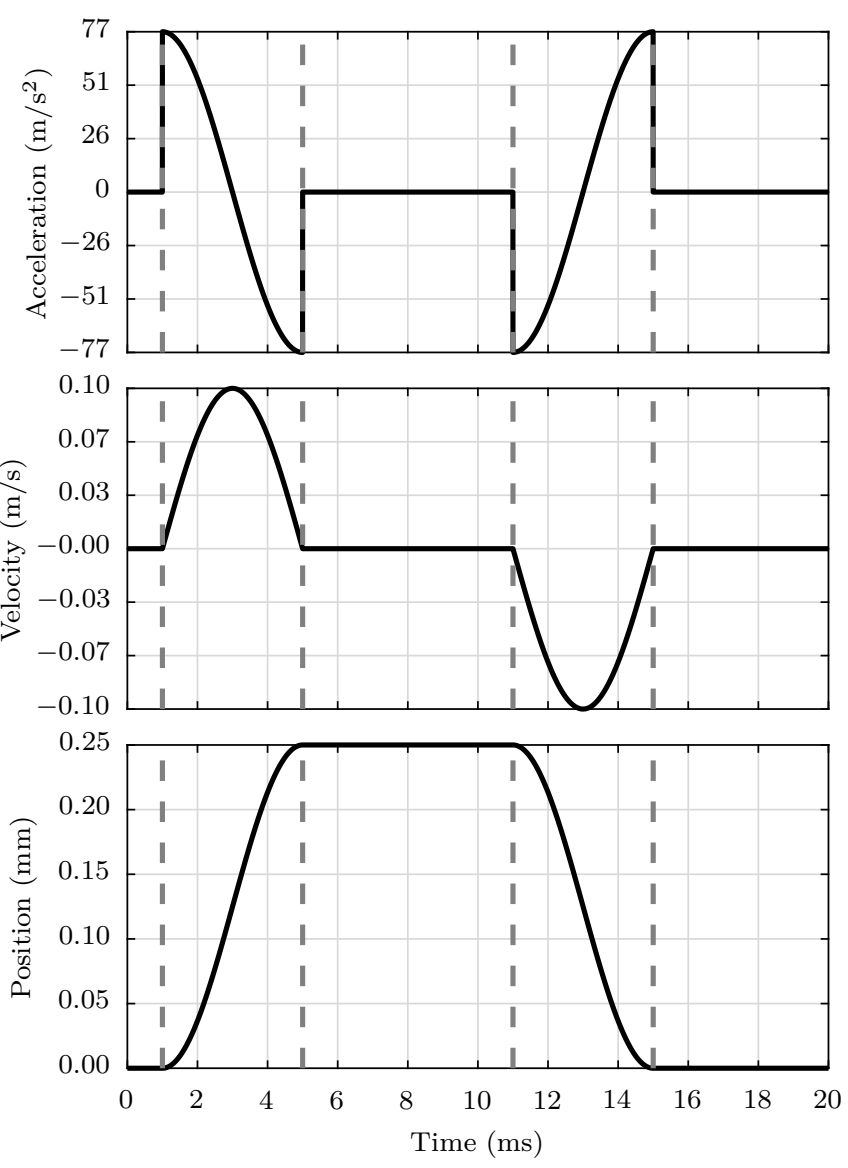

Fig. 2. Valve motion profile with the (a) acceleration, (b) velocity, and (c) position reference.

A reluctance actuator consists of an electrical, a magnetic, and a mechanical subsystem. Representing the coil as a series RL-circuit, the voltage to current transfer function used in the inner control loop is

$$
I(s)=\frac{1}{s L+R} V(s),
$$

where a constant inductance, $L$, and resistance, $R$, are assumed. Worst-case conditions are considered by using the minimal inductance value, consequently, the (change in) current is continuously overestimated. Note that the emf is neglected because of the low speed of movement (see Fig. 2).

The transfer function between position, $Z(s)$, and net force, $F_{\mathrm{mot}}$, in the outer control loop is

$$
Z(s)=\frac{1}{m s^{2}} F_{\operatorname{mot}}(s),
$$

where $m$ is the total moving mass, and $F_{\text {mot }}$ is the net force on the moving mass. The latter is obtained as

$$
F_{\text {mot }}(z, i)=F_{\text {em }}(z, i)-F_{\text {opp }}(z),
$$

where $F_{\mathrm{opp}}(z)$ is the opposing force resulting from the oil and return spring, and $F_{\mathrm{em}}(z, i)$ is the electromagnetic 
TABLE I. Comparison of controller performance.

\begin{tabular}{lccc}
\hline \hline & Target & On-off & Cascaded control \\
\hline Opening time $[\mathrm{ms}]$ & 4 & 0.3 & 3.8 \\
Impact velocity $\left[\mathrm{m} \mathrm{s}^{-1}\right]$ & $<0.1$ & 2.3 & 0.06 \\
Maximal current $[\mathrm{A}]$ & - & 7.7 & 1.8 \\
\hline \hline
\end{tabular}

reluctance force produced by the actuator. This force results from nonlinear, magnetostatic finite element (FE) simulations where the axial symmetry of the actuator is used to reduce the problem complexity. These simulation results are used to populate lookup tables (LUTs) to allow for fast simulations.

The above transfer functions have been used as the plants in a loop-shaping algorithm to design the feedback controllers using root-locus diagrams and Bode plots. Closed-loop objectives are a settling time smaller than $0.2 \mathrm{~ms}$ and $4 \mathrm{~ms}$ for the current and position controller, respectively. As such, current control acts an order of magnitude faster than position control which allows variations in the coil current to have a minimal effect on the position tracking capabilities.

\section{Simulation RESUlts}

Comparison of the simulation results for an uncontrolled (voltage on-off) motion and the motion resulting from the cascaded position and current control is shown in Fig. 4, and performance metrics are summarized in Table I. For the cascaded control, the closed-to-open transition time is increased tenfold, while the impact velocity is reduced several orders of magnitude to less than $0.1 \mathrm{~m} \mathrm{~s}^{-1}$, i.e. a soft landing is achieved and the motion is completed within the maximal time $(4 \mathrm{~ms})$. In addition, the cascaded control reduces the power consumption drastically as well, considering the maximally attained coil current in both the uncontrolled and the cascaded scenario.

\section{DISCUSSION}

Cascaded feedback control is applied to simulations of a low-energy solenoid valve actuator and a softlanding, timely actuation, and reduced power consumption are achieved.

Nonlinear, magnetostatic finite element simulations have been used to populate lookup tables (LUTs) for the electromagnetic force. Such LUTs have not been used for the relation between plunger position (airgap), coil current, and inductance. Instead, a constant inductance is assumed during controller design, to allow for controller design through loop-shaping. In addition, ideal position measurement and feedback is assumed, while in the real application, position reconstruction is considered as in [6]. This technique relies on the measurement of electrical quantities at the coil terminals, and reconstructing the plunger position based on known relations between voltage, (change of) current, and inductance (or flux linkage). Such reconstruction is preferred over position measurement because of the wet environment and the limited available space around the plunger. Control based on the measurement of the airgap flux is a possible improvement to the approach presented in this paper. Especially at smaller movements and for increased demanded accuracy, accounting for the hysteresis in the soft-magnetic material in reluctance actuators becomes increasingly important [9, pp.24].

Another practical implementation aspect concerns the sampling frequency that is required by the high-gain, high-bandwidth current controller. The simulated results have been obtained at a sampling frequency of $200 \mathrm{kHz}$, which means that in practice, an even higher frequency is required for reliable measurements. The designed current controller allows to track a third-order current setpoint which is necessary because of the steepness of the forcecurrent relation. As can be observed from the results, a $0.2 \mathrm{~mA}$ mismatch between desired and delivered current cause the observed position errors. This indicates the complexity of the control, and how precisely the LUTs have to be populated.

\section{CONCLUSIONS AND FUTURE WORK}

Cascaded position- and current-feedback control is designed and implemented on simulations of a lowenergy solenoid valve actuator. Actuator performance is improved considerably, as a soft landing, a timely actuation, and an increased energy-efficient device have been obtained. The reluctance actuator considered in this paper has been modeled using nonlinear, magnetostatic finite element (FE) simulations, the results of which populate lookup tables (LUTs) to relate plunger position (magnetic airgap), coil current, and the electromagnetic, attractive reluctance force.

Preliminary transient finite element analyses (not included here) have shown that open-loop control using predefined voltage profiles results in high energy consumption and no soft-landing. Furthermore, the eddy current effects further deteriorate the timing performance and increase the losses. Therefore, future research will focus on introducing a permanent magnet (PM) in the actuator to reduce energy consumption at larger duty cycles, see Fig. 1b. Simulations will be performed using 


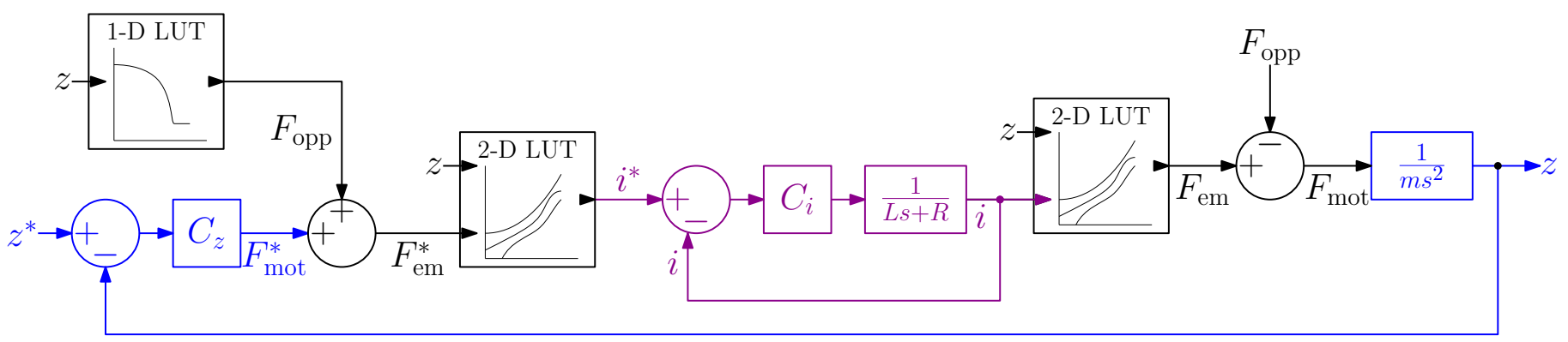

Fig. 3. Control scheme indicating the inner current control, $C_{\mathrm{i}}$ (magenta), and the outer position control, $C_{\mathrm{z}}$ (blue).
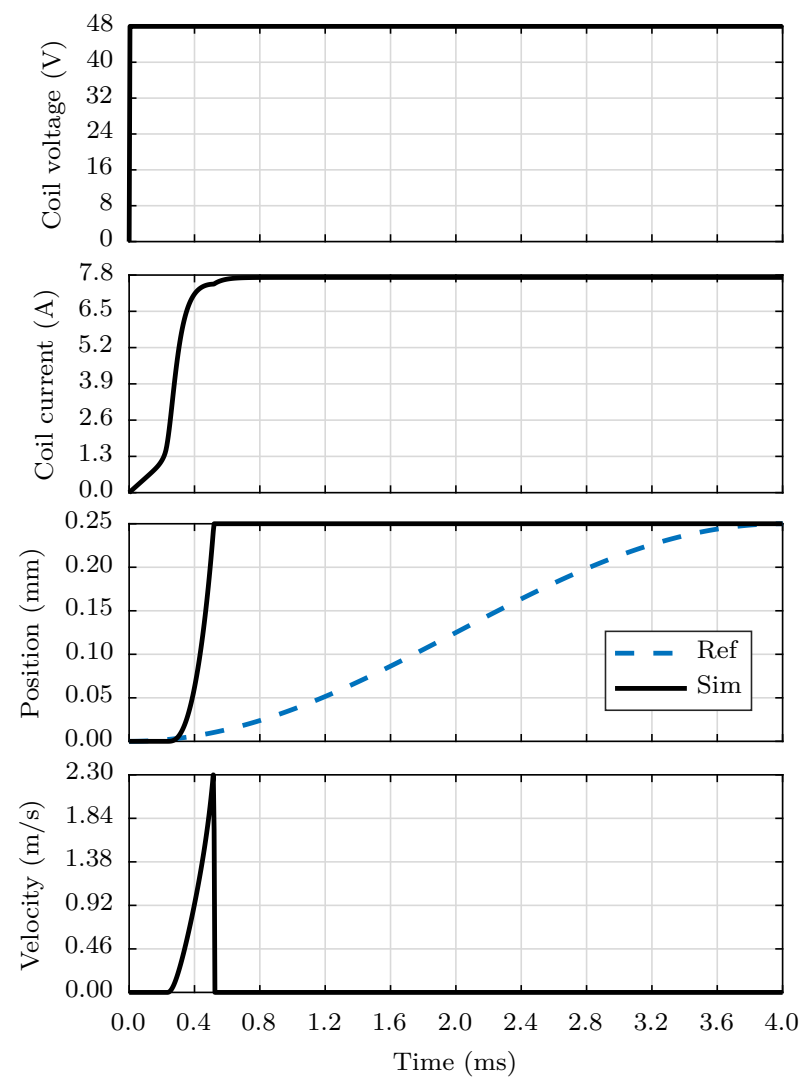

(a)
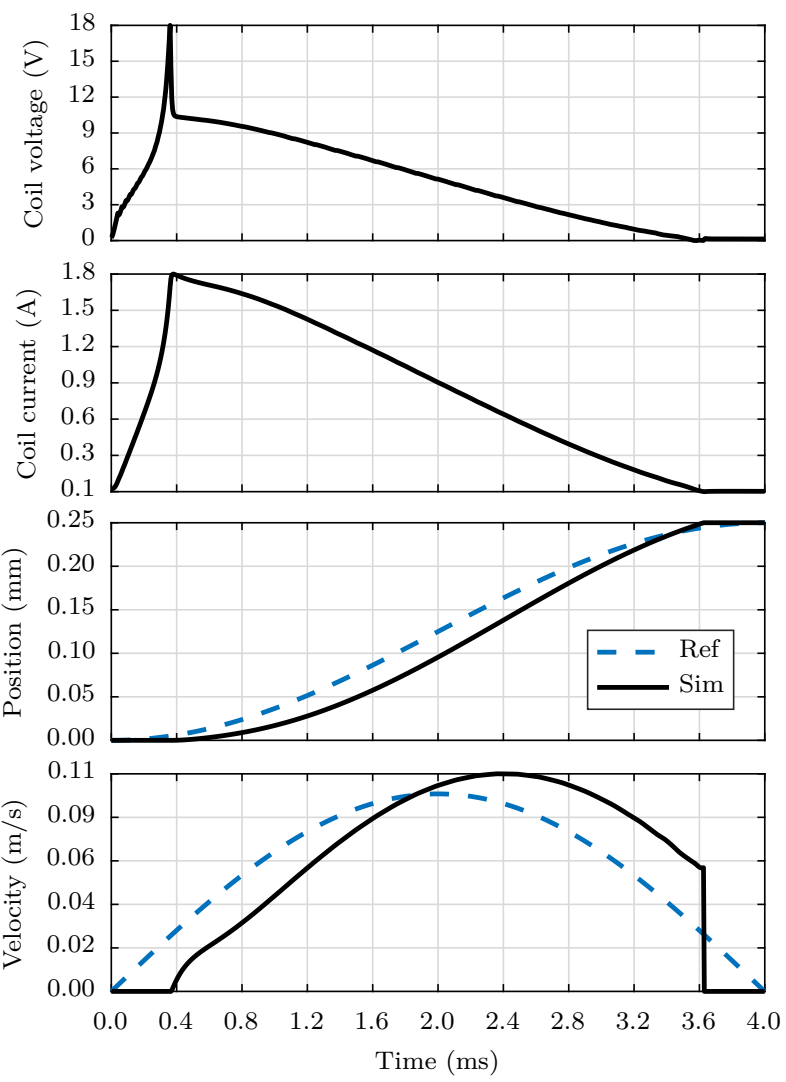

(b)

Fig. 4. Comparison of the simulation results for the opening motion for (left) an uncontrolled (voltage on-off) design and (right) the motion resulting from the cascaded position and current control.

a closed-loop co-simulation using Matlab-Simulink and transient FE software incorporating eddy current effects. These simulations will be performed on both actuator types and analysis will target possible reduction of energy consumption and maintaining the ability to achieve soft-landing.

\section{ACKNOWLEDGMENT}

This project has received funding from ECSEL JU under grant agreement No. 662192 (project 3Ccar).

\section{REFERENCES}

[1] B. V. Ravi Kumar, K. Sivakumar, Y. Srinivas Rao, and S. Karunanidhi (2017), "Design of a new electromagnetic brake for actuator locking mechanism in aerospace vehicle," in IEEE Transactions on Magnetics, vol. 53, no. 11, pp. 1-6.

[2] T. Glück, W. Kemmetmüller, and A. Kugi (2011), "Trajectory optimization for soft landing of fast-switching electromagnetic valves," in Proceedings of the 18th IFAC World Congress, vol. 18, pp. 11532-11537.

[3] F. Mach and T. Kaminský (2016), "Novel monostable failsafe electromagnetic actuator for straight valve in high-speed operation," in 2016 ELEKTRO, Strbske Pleso, pp. 186-191. 
[4] W. Hoffmann, K. Peterson, and A. G. Stefanopoulou (2003), "Iterative learning control for soft landing of electromechanical valve actuator in camless engines," in IEEE Transactions on Control Systems Technology, vol. 11, no. 2, pp. 174-184.

[5] R. E. Clark, G. W. Jewell, P. Stewart, and D. Howe (2002), "Tailoring force-displacement characteristics in medium-stroke linear variable reluctance actuators," in IEEE Transactions on Magnetics, vol. 38, no. 5, September, pp. 3267-3269.

[6] E. Ramirez-Laboreo, C. Sagues, and S. Llorente (2017), "A new run-to-run approach for reducing contact bounce in electromagnetic switches," in IEEE Transactions on Industrial Electronics, vol. 64 , no. 1 , pp. 535-543.
[7] M. F. Rahman, N. C. Cheung, and Khiang Wee Lim (1996), "Position estimation in solenoid actuators," in IEEE Transactions on Industry Applications, vol. 32, no. 3, pp. 552-559.

[8] B. Gysen, S. Gibson, R. Clark, and G. Jewell (2007), "High temperature permanent magnet actuator for fail-safe applications," in IEEJ Transactions on Industry Applications, vol. 124, no. 1, pp. 1-4.

[9] A. Katalenic (2013), "Control of reluctance actuators for highprecision positioning," $\mathrm{PhD}$ dissertation, Eindhoven University of Technology. 